\title{
Gender Differences in Motivation and Learning Preferences of Pharmacists in Lifelong Learning
}

\author{
Sharon Louise Njet-Moi Tjin A Tsoi ${ }^{1}$, Anthonius (Ton) de Boer ${ }^{2}$ and Andries Koster ${ }^{2}$ \\ 1. PAOFarmacie, Netherlands Centre for Post-Academic Education in Pharmacy, Zeist, The Netherlands \\ 2. Department of Pharmaceutical Sciences, Utrecht University, Utrecht, The Netherlands
}

\begin{abstract}
Objectives: To analyse motivation and preferences of pharmacists who participate in CE (continuing education) to develop suitable lifelong learning programmes for pharmacists. Methods: An online questionnaire, which explored the motivation and preferences of the pharmacists to lifelong learning, was sent to all members of the Royal Dutch Pharmaceutical Society (4321) in the Netherlands. The data were analysed using a non-hierarchical clustering technique. Key findings: Two clusters of pharmacists were discovered. Cluster A pharmacists $(n=474)$ were more motivated by credit points $(63.5 \%$ vs. $47.2 \%)$, personal interest $(84.1 \%$ vs. $56.3 \%)$, updating knowledge (73.8\% vs. $56.8 \%)$ and topicality of CE courses $(47.7 \%$ vs. $26.1 \%)$. Cluster B pharmacists $(n=199)$ were predominantly motivated by the aspect "duty as a care-giver" ( $97.0 \%$ vs. $0 \%$ in cluster A). Pharmacists who belonged to cluster A tended to be women $(60.5 \%)$, often worked part-time $(29.3 \%)$ and mostly preferred lectures $(71.1 \%)$. Cluster B pharmacists consisted of statistically significantly more male pharmacists $(52.8 \%, p=0.001)$, worked more full time $(77.4 \%, p=0.009)$ and mostly preferred blended learning $(62.3 \%, p=0.047)$. Conclusions: These results suggest the use of different education formats for different kinds of pharmacists to participate in CE activities.
\end{abstract}

Key words: Continuing education, continuous professional development, lifelong learning; motivation, gender differences, pharmacists.

\section{Introduction}

Traditional lifelong learning in pharmacy is based on $\mathrm{CE}$ (continuing education). $\mathrm{CE}$ is a system of organized learning experiences and activities in which pharmacists participate after their academic training. This system is designed to maintain competencies in order to provide quality service, patient care to enhance problem solving and critical thinking applicable to the practice of pharmacy [1]. More recently, countries like Canada, the United Kingdom and Australia are shifting from a CE system to a system of CPD (continuous professional development) [2]. CPD has been defined as systematic, ongoing, self-directed learning and is designed to ensure the maintenance of knowledge, skills and competencies of the pharmacists throughout their careers (Fig. 1) [1, 2].

Corresponding Author: Sharon Louise Njet-Moi Tjin A Tsoi, Pharm.D., research field: medical and pharmaceutical education. E-mail: s.schouten@paofarmacie.nl.
$\mathrm{CE}$ can be seen as a part of the CPD process. CPD is known to increase pharmacists' perceptions of pharmacy practice as a result of their education activities compared with pharmacists who participated in traditional CE [3].

Research about the perceptions, engagement and barriers of pharmacists to participate in $\mathrm{CE}$ and $\mathrm{CPD}$ shows that the profession generally accepts that CPD is essential, but there is a wide variation in participation and attitudes towards future proposals for CPD [5]. Barriers in both CE and CPD, such as lack of time and motivation were found [1, 6-8]. Remuneration, locum cover and lack of understanding of CPD were also identified as barriers to participate in CPD [8]. Laaksonen et al. [6] suggested that pharmacists may need support to engage fully in CPD.

Pharmacy practice in the Netherlands is regulated by the Royal Dutch Pharmaceutical Society (KNMP). At present, the Dutch system is a traditional CE-system. 


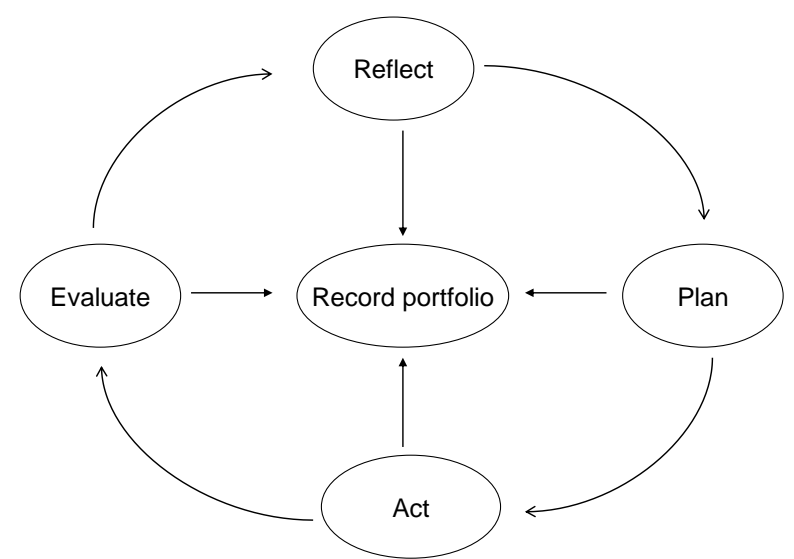

Fig. 1 Continuing professional development cycle centered around a portfolio.

This figure describes CPD in a statement adopted by FIP in 2002 [4].

Pharmacy graduates follow a registration training of two years to become a community pharmacist or a specialisation training of four years to become a hospital pharmacist. After, registration pharmacists are required to re-register and are awarded credit hours for accredited activities. At least 200 accredited $\mathrm{CE}$ hours are required during a period of five years to maintain licensure. Recently, the KNMP introduced a CPD format for the specialisation training for community pharmacists. In the future, the pharmacists will have to keep their records in a portfolio and the specialisation will be completed with an assessment.

Donyai et al. [9] reviewed participation and beliefs of pharmacy professionals towards CPD in Great Britain during a formal transition from CE to CPD. Again, motivation and (lack of) interest in CPD were two of the eight barriers identified in this review.

In lifelong learning, we are facing a major challenge of keeping the pharmacists motivated for at least 35 years. This is an important reason why it is relevant to know more of the nature of adult motivation and learning in this context.

Getting insight in the motivation and preferences of pharmacists towards lifelong learning will be useful for all countries that are shifting from CE to CPD.

Many studies from the early elementary school to adult education have been conducted to analyze how learning is influenced by motivational factors [10-13].

Motivation can be distinguished in intrinsic and extrinsic motivation. Intrinsic motivation is driven by interest and joy in the task itself and exists within the individual. Extrinsic motivation comes from outside the individual and is driven by external rewards like grades received or financial incentives. Ryan and Deci's SDT (self determination theory) describes how lack of motivation (amotivation) can develop into intrinsic motivation through different stages of extrinsic motivation [12]. They defined the following stages of extrinsic motivation: external regulation, introjected regulation, identified regulation and integrated regulation. External regulation is the least self-determined stage and integrated regulation is the most. This theory focuses on the basis psychological needs that are inherent in human life: the need for competence, relatedness and self-determination (or autonomy).

Regarding the "Purpose-Action-Results" as a behavioural model from Alexander et al. [14] there are two types of CPD behaviour. One is externally driven and in line with main CE-type activities; the other represents a connection with experiential learning from Kolb [15]. Keeping this in mind, we believe that motivation will lead to significant consequences regarding the participation of pharmacists and thus the success of CPD. Therefore, it is important to understand how the development of intrinsic motivation can be supported as much as possible.

Gender issues are generally poorly studied in lifelong learning. A possible explanation is the current individualisation of society which doesn't allow general constructs such as gender [16]. In studies of the engagement in lifelong learning in pharmacy, the following gender differences were found. Mottram et al. [5] found that female pharmacists participated in statistically significantly more hours of CE (30 hours versus 20 hours in 12 months). Driesen et al. [17] determined differences in motivators and barriers according to gender. Female pharmacists were 
motivated by presents, while men were more likely to enjoy the activity itself. Barriers as "distance to the class" and "reluctance to make the trip" apply more significantly for women compared to their male colleagues. Men feel hindered by "coincidence with other (e.g., sports) activities", while women feel more inhibited by "family commitments". This same barrier "to feel torn between family and work commitments" was identified for female pharmacists by Laaksonen et al. [6] and Hull [18]. In contrast, for male respondents, "business commitments" was a disincentive for attendance. In Hanson's study [19], women indicate to have a greater personal desire to learn than their male counterparts.

The aim of this study is to get insight in the motivation and preferences of pharmacists for lifelong learning in the Netherlands. By profiling pharmacists based on their motivation and preferences for $\mathrm{CE}$ courses, we try to understand how we can engage pharmacists in a system of CPD. Previous motivation research is mostly based on the barriers to participate in CE and CPD [6-8, 19]. Unlike these earlier studies, we do not ask for the experienced barriers. Instead, we choose to ask the pharmacists what motivates them to participate in a CE course.

By clustering pharmacists in subgroups and characterizing these groups that have similar response patterns, we may be able to develop appropriate courses aimed at these subgroups.

The research questions of this study are: Can pharmacists be profiled based on their learning preferences? If yes, what are the differences in motivational aspects between these clusters?

\section{Method}

\subsection{Setting}

The study was performed among members of the Royal Dutch Pharmaceutical society (KNMP). Although it is not officially known by the KNMP how many Dutch pharmacists are a member, it is general assumed that this number is above $90 \%$.

\subsection{Study Design}

A cross sectional study with an online questionnaire was conducted. Pharmacists were invited to participate in the study by a letter from the head of the department of Pharmaceutical Sciences of Utrecht University.

\subsection{Participants}

All pharmacist members were selected from the database of the KNMP. For the present study, only the data from the community and the hospital pharmacists were used, because these are the main target groups to participate in CE courses. The excluded were pharmacists working in the pharmaceutical industry, at the university, at the KNMP, in postgraduate education and others.

\subsection{Questionnaire}

An online questionnaire (Table 1), which could be completed in approximately 10 minutes, was sent to 4,321 pharmacists and was online for two weeks (January 2011). After one week, a reminder was sent. Pharmacists were given the opportunity to receive, as an incentive, a free leisure magazine of choice.

Motivation was measured by asking the pharmacists what motivated them to participate in a CE-course. Preference was measured in two ways, namely, the CE-format and the choice of themes.

Other things asked were demographics like gender, current practice setting, hours working in practice, university where pharmacy degree was obtained and number of years working in practice. When there were multiple answers to choose from, pharmacists could fill up a minimum of one and a maximum of three answers. If the predefined answers were not relevant to the pharmacist, there was a possibility to fill in their own motivation or preference. All questions and answers were designed to collect categorical/nominal data. The questionnaire was piloted by a group of five people existing of practicing pharmacists and teachers, working at the University of Utrecht and involved in 
Table 1 Characteristics of survey respondents.

\begin{tabular}{|c|c|c|}
\hline Characteristic & Number of respondents & $\%$ \\
\hline \multicolumn{3}{|l|}{ Gender } \\
\hline Female & 381 & 57 \\
\hline Male & 292 & 43 \\
\hline \multicolumn{3}{|l|}{ Current practice setting } \\
\hline Community pharmacy & 531 & 79 \\
\hline Hospital pharmacy & 142 & 21 \\
\hline \multicolumn{3}{|l|}{ Hours working in practice } \\
\hline Less than 24 hours & 25 & 4 \\
\hline 24-32 hours & 175 & 26 \\
\hline More than 32 hours & 473 & 70 \\
\hline \multicolumn{3}{|l|}{$\begin{array}{l}\text { University where Pharmacy } \\
\text { degree was obtained }\end{array}$} \\
\hline University of Utrecht & 369 & 55 \\
\hline University of Groningen & 217 & 32 \\
\hline University of Amsterdam* & 26 & 4 \\
\hline University of Leiden* & 39 & 6 \\
\hline Elsewhere & 22 & 3 \\
\hline \multicolumn{3}{|l|}{ Length of time in practice } \\
\hline Less than 5 years & 109 & 16 \\
\hline $5-10$ years & 153 & 23 \\
\hline $11-15$ years & 130 & 20 \\
\hline $16-20$ years & 91 & 14 \\
\hline $21-25$ years & 84 & 12 \\
\hline 26 years and more & 106 & 15 \\
\hline
\end{tabular}

*The number of pharmacists responded from these two cities are substantially less in comparison with Utrecht and Groningen because Pharmacy education ended around 1990 in Amsterdam and Leiden.

CE, and adjusted accordingly.

\subsection{Data Analysis}

Kaufman and Rousseeuw 1990 [20] defined cluster analysis as "the classification of similar objects into groups where the number of groups as well as their forms, are unknown". Cluster criteria involve minimizing the within-cluster variation and maximizing the between-cluster variation. The advantage of clustering on statistical grounds is that the choice of the cluster criterion is less arbitrary [21].

At first, the data were analysed based on the categories of motivation and preferences using the two-step cluster method where the number of clusters is automatically determined. After concluding that this method was not useful, we used a non-hierarchical K-means clustering technique to categorize the pharmacists. The K-means method moves records iteratively from one cluster to another, starting from an initial partition. The cluster groups were based on the response given at the motivation question. Eventually, we discovered that a two-step cluster method was the most consistent method. To see whether the classification was robust, we repeated cluster analysis with $50 \%$ and $75 \%$ random subsets of the data and analyzed whether clustering of the subsets and the original full set of data were consistent. A categorical log-likelihood ratio statistic was used to determine whether the differences between the clusters were significant or not. Differences between clusters were analysed using Chi-square tests.

Cross tables were made between the two clusters and the following variables: gender, current practice setting, hours working in practice, university where pharmacy degree was obtained, length of time in practice, preferences in CE-format and choice of themes and sufficient knowledge yes/no.

All statistical tests were two-tailed and based on a significance level of $\alpha<0.05$. All data analyses were conducted using SPSS release 18.0

\section{Results}

From the 4,321 members of the KNMP, 889 (nearly $21 \%$ ) completed the questionnaire. From the 889 respondents, $59.7 \%$ were community and $16.0 \%$ were hospital pharmacists; 216 respondents were excluded because they were working in the pharmaceutical industry, at the university, at the KNMP, in postgraduate education or elsewhere, resulting in a final sample of 673 respondents (Table 2).

Fig. 2 shows that the most important differences between the two clusters in motivation were "credit points" ( $\chi 2=15.3, p<0.001)$, "personal interest" $(\chi 2$ $=59.7, p<0.001)$, "updating knowledge" $\left(\chi^{2}=19, p\right.$ $<0.001)$, "it is my duty as a care-giver" $(\chi 2=644.6, p$ $<0.001)$ and "topicality of subject" $\left(\chi^{2}=26.8, p<\right.$ 
0.001). Cluster A pharmacists were mainly motivated by "credit points", "personal interest", "updating knowledge" and "topicality of subject" to attend to CE courses. Cluster B pharmacists were predominantly motivated to participate in $\mathrm{CE}$ by their perceived duty as a care-giver.

Table 3 shows that pharmacists of cluster A and B significantly differed in the following aspects: gender-composition, part-time versus full-time working and preference for lectures or blended learning. Pharmacists who belonged to cluster A tended to be more women who worked often less than $32 \mathrm{~h}$ per week and preferred lectures while pharmacists in cluster B consisted of statistically significant more male pharmacists who tended to work more full time and preferred blended learning.

The university where the pharmacy degree was obtained, the practice setting (community or hospital pharmacists) and the length of time in practice were of no influence on the characterisation of the two clusters (data not shown).

Table 2 The two most important questions of the survey conducted in January 2011.

Questions about the motivation and preference of pharmacists.

\section{(1) Credit points}

(2) The subject is of my personal interest

(3) I don't know enough of this

What is in general your subject and want my knowledge motivation to attend to updated

a CE-course? (4) It is my duty as a caregiver

(5) The KNMP* asks me to do this

(6) The subject is topical

(7) It is important to meet my peers (8) Otherwise...

(1) Lectures

(2) Blended learning

What type of (3) Workshops

post-academic education is your

(4) Learning through the web

(5) Workplace learning preference?

(6) Distance learning by writing

(7) Peer groups

(8) Otherwise...

*KNMP $=$ the Royal Dutch Pharmaceutical Society.

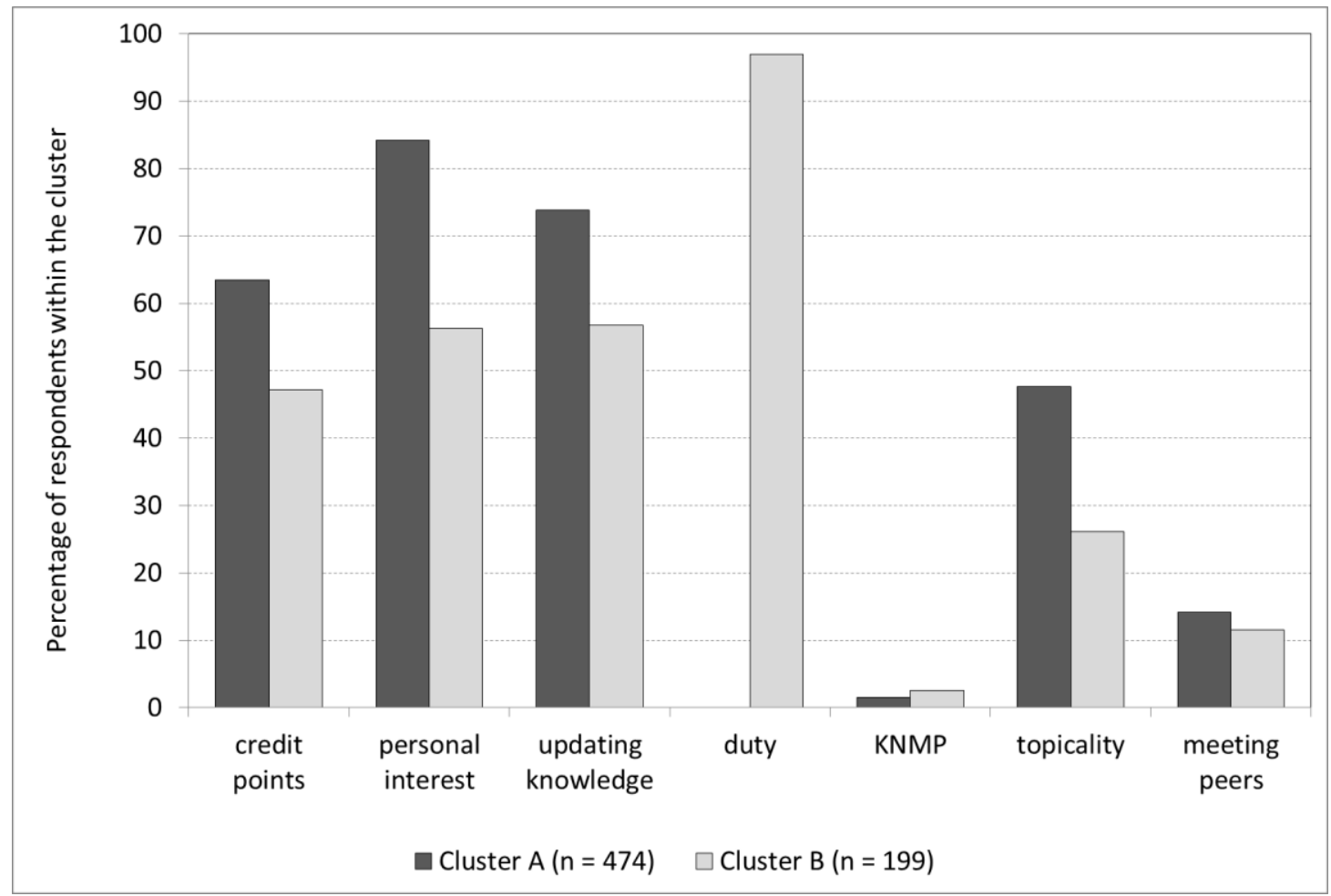

Fig. 2 Frequencies of pharmacists in cluster A versus B based on motivational aspects.

Cluster A consists of 474 pharmacists and cluster B of 199 pharmacists. The frequencies of the pharmacists related to the motivational aspects were respectively: motivated by credited points (301 versus 94), personal interest (399 versus 112), updating their knowledge ( 350 versus 113 ), *duty as a care-giver ( 0 versus 193$)$, demanded by the KNMP (7 versus 5 ), **topicality of the subject 226 versus 52) and meeting their peers (67 versus 23 ). 
Table 3 Characterisation of clusters $A$ and B, based on demographics and learning preferences.

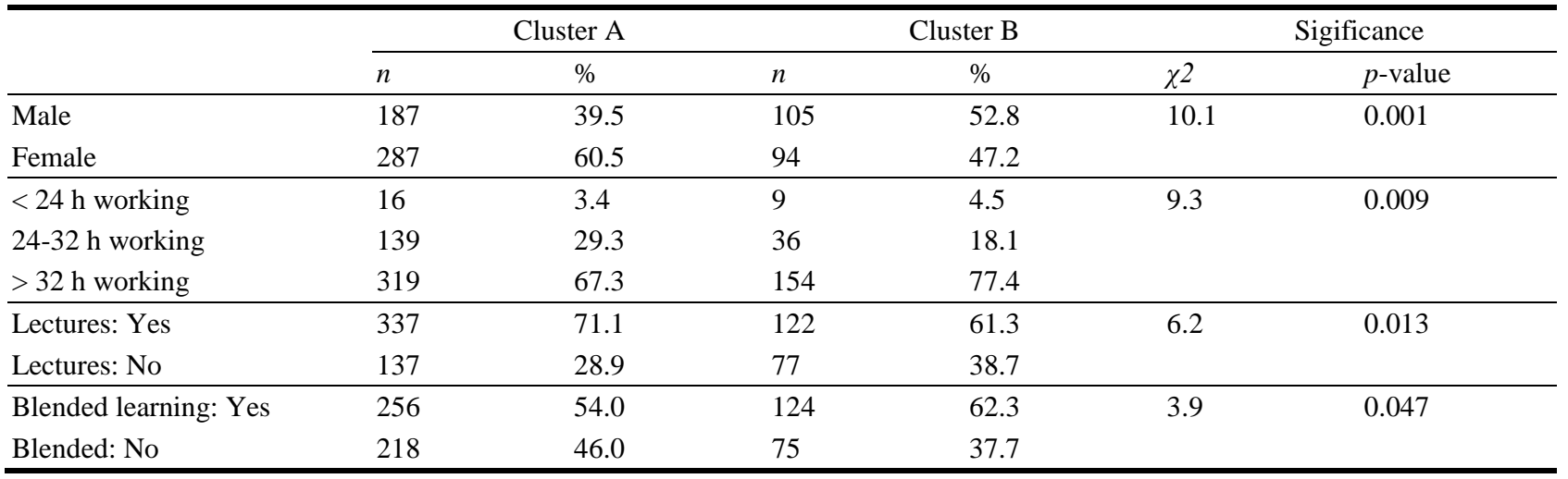

\section{Discussion}

Two motivational clusters of pharmacists were apparent which differed significantly. One cluster consisted of more female pharmacists who worked relatively more part-time and preferred lectures; the other cluster included more male pharmacists who worked full-time and preferred blended learning.

In the introduction, we already explained the generation of the clusters, namely, to try to develop appropriate courses aimed at these subgroups. After clustering the data with the two-step cluster method in many different ways, we concluded there were too many possible clusters (range from 5 to 12) to be useful for our study. Since it is more pragmatic as a provider for postgraduate courses to aim at two or three subgroups than at twelve, we decided to use the $\mathrm{K}$-means clustering algorithm. With this technique, it is possible to rapidly divide a large number of variables into tight clusters. A potential disadvantage of using this type of analysis is the consistency of the clusters. The possibility exists that variation of the dataset can provide different cluster memberships of the studied cases. For this reason, we ran the analysis with a $50 \%$ and a $75 \%$ random subset. In the 50\% subsets, $100 \%$ of the cases ended up in the same cluster as in the full dataset. In the $75 \%$ subsets, less than $1 \%$ of the cases differed from the clusters as in the full dataset.

The results of this study show that a distinguishing characteristic between cluster A and B is gender. As pointed out before, little is known about gender issues in lifelong learning. Our results are similar to what was found by Driesen et al. for the preferences of female pharmacists. They also found that pharmacists who preferred lectures were more likely to be female. At the same time, this group was moderately motivated to participate in CE courses. Because our cluster A pharmacists, which are more female, seems to be more motivated by credit points than our cluster B pharmacists (more male) and it suggests that female pharmacists are more extrinsically motivated. This result seems to be contradictory to previous results because in general intrinsic motivation in women is found to be more common than that in men [22]. As mentioned earlier by Hull et al [18], and Mottram et al. [7], they found that women undertook more CE and CPD. Furthermore, Hanson [19] found that females indicate to have a greater personal desire to learn than men.

In a review on gender differences in learning styles of students who were 18 years old and older, a small but consistent difference between men and women was reported [22]. Men preferred the abstract conceptualisation mode of learning and were more extrinsically motivated. Women on the contrary were more intrinsically motivated, but showed more often a surface or reproductive approach to learning. Even though these small differences were found, the review did not result in a clear and coherent picture of gender differences. It is also found that research results vary widely and are at times contradictory. 
From Ryan and Deci's [23] point of view, "feeling of competence" and "self-determination" are important factors enhancing intrinsic motivation. Could it be that the women in our study felt less competent because they mostly work part-time? As women stated that family came first $[6,17,18]$, could it be that these constraints are such a great barrier that their autonomy is threatened? Although a growing number of women are working on their career in the Netherlands, still most of them are in charge of their children. We can imagine that women make their choices based on family priorities. This can explain why our female respondents preferred lectures and were more motivated by credited points than their male counterparts.

We should be careful to interpret these results as applying to all men and women. Differences between genders can be possible, but differences within these groups can go beyond those between the groups. More research is needed in which gender differs in learning orientations and motivation. We also need to explore the deeper reasons of our results.

In the UK, US, Australia, Ireland, Scotland, Belgium and Qatar, studies among pharmacists' experiences and perception of lifelong learning delivered some insight in barriers and facilitators of participation. [5-8, 19, 24, 25] Nevertheless it is still needed to further clarify the characteristics of pharmacists regarding their motivation and preferences in lifelong learning. This is the first time a similar study was conducted in the Dutch setting.

An important limitation of this study is that it was conducted in a traditional CE system and not in a CPD system. Previous research was done to explore the participation of pharmacists in CE and simultaneously determine their attitudes towards CPD [5]. On the other hand, when we compared different studies which determined the most important barriers in CE- or CPD-context, no major differences are observed. Time/job constraints, location, family responsibilities, relevance of courses and financial incentives are the most important barriers in both $\mathrm{CE}$ and $\mathrm{CPD}[6,8]$. Further research needs to confirm the value of these results when implementing in a future CPD system. To improve engagement in future CPD, we also have to take into account informing pharmacists how CPD works and supports them [6].

It can be questioned if this method of data collection was the best method because of our low response rate. However, other studies using web-based surveys at assessing needs, barriers and preferences of pharmacists in lifelong learning also had response rates between $20 \%-25 \%$ [5, 25, 26].

For representativeness, we compared our participants with the data from the KNMP. The KNMP registers $49.4 \%$ male pharmacists (respondents $43 \%$ ) and $50.6 \%$ female pharmacists (respondents 57\%). In the current practice setting, the KNMP register $81.9 \%$ community pharmacists (this study $79 \%$ ) and $18.1 \%$ hospital pharmacists (this study $21 \%$ ). Even if the ratios of the respondents are similar to the KNMP-membership data, there is a risk of bias. There is a possibility that pharmacists, who do less or not participate and are less or not motivated for $\mathrm{CE}$, did not respond to the survey.

\section{Conclusions}

With this study, we describe characteristics of pharmacists according to their motivation and preferences for lifelong learning. This is the first study conducted with Dutch pharmacists. The clusters A (mainly motivated to attend to CE courses by credit points, personal interest, updating knowledge and topicality of subject) and B (predominantly motivated to participate in $\mathrm{CE}$ through their duty as a care-giver) differed significantly in gender, hours working and preferences for educational formats. Although there were significant differences, cluster-separation was not complete.

Based on these results, it seems desirable to provide different education formats per theme. This could lead to a layered lifelong learning system with different 
levels. We also need to inform and support the pharmacists properly to improve their engagement in a future CPD-system. How to differentiate the curriculum and to what extent we should differentiate will be studied in further research.

\section{References}

[1] Rouse, M. J. 2004. "Continuing Professional Development in Pharmacy." American Journal of Health-System Pharmacy 61: 2069-76.

[2] Driesen, A., Verbeke, K., Simoens, S., and Laekeman, G. 2007 "International Trends in Lifelong Learning for Pharmacists." Am. J. Pharm. Educ. 71: 52.

[3] McConnell, K. J., Newlon, C. L., and Delate, T. 2010. "The Impact of Continuing Professional Development versus Traditional Continuing Pharmacy Education on Pharmacy Practice." Ann. Pharmacother. 44: 1585-95.

[4] International Pharmaceutical Federation, 2002, Nice. "FIP Statement of Professional Standards Continuing Professional Development." http://www.fip.org/www/uploads/database_file.php?id=2 21\&table_id=.

[5] Mottram, D. R., Rowe, P., Gangani, N., and Al-Khamis, Y. 2002 "Pharmacists' Engagement in Continuing Education and Attitudes towards Continuing Professional Development." Pharmaceutical Journal 269: 618-22.

[6] Laaksonen, R., Duggan, C., and Bates, I. 2009 "Overcoming Barriers to Engagement in Continuing Professional Development in Community Pharmacy: A Longitudinal Study." Pharmaceutical Journal 282: 44-8.

[7] Marriott, J., Duncan, G. J., and Mc Namara, K. P. 2007. "Barriers to Pharmacist Participation in Continuing Education in Australia." Pharmacy Education 7: 11-7.

[8] Bell, H. M., Maguire, T. A., and McGartland, L. F. 2002. "Perceptions of Continuing Professional Development within the Pharmacy Profession." Journal of Social and Administrative Pharmacy 19: 87-98.

[9] Donyai, P., Herbert, R. Z., Denicolo, P. M., and Alexander, A. M. 2011. "British Pharmacy Professionals' Beliefs and Participation in Continuing Professional Development: A Review of the Literature." International Journal of Pharmacy Practice 19: 290-317.

[10] Krapp, A. 1999. "Interest, Motivation and Learning: An Educational-Psychological Perspective." European Journal of Psychology of Education 14:23-40.

[11] Ahl, H. 2006. "Motivation in Adult Education: A Problem Solver or a Euphemism for Direction and Control?" International Journal of Lifelong Education 25: 385-405.

[12] Deci, E. L., Vallerand, R. J., Pelletier, L. G., and Ryan, R. M. 1991. "Motivation and Education: the
Self-determination Perspective." Educational Psychologist 26: 325-46.

[13] Bandura, A., and Schunk, D. H. 1981 "Cultivating Competence, Self-efficacy, and Intrinsic Interest through Proximal Self-motivation." Journal of personality and social psychology 41: 586-98.

[14] Alexander, A. M., Denicolo, P. M., and Donyai, P. 2011 "Purpose-Action-Results as a Behavioural Model: Telling the Story of Pharmacy Professionals' Continuing Professional Development." International Journal of Pharmacy Practice. 19 (S): 13-5.

[15] Kolb, D. A. 1984. Experiential Learning: Experience as the Source of Learning and Development. NJ: Prentice-Hall: Upper Sadle River.

[16] Rogers, A. 2006. "Lifelong Learning and the Absence of Gender." International Journal of Educational Development 26: 189-208.

[17] Driesen, A., Simoens, S., and Laekeman, G. 2008 "Continuing Education Programs for Pharmacists: No One Size Fits All.” Pharmacy Education 8: 37-43.

[18] Hull, H., and Rutter, P. 2003 "A Cross Sectional Survey of UK Community Pharmacists' Views on Continuing Education and Continuing Professional Development." International Journal of Educational Development 1 (2): $1-12$.

[19] Hanson A. L, Bruskiewitz, R. H., and DeMuth J. E. 2007. "Pharmacists' Perceptions of Facilitators and Barriers to Lifelong Learning." Am. J. Pharm. Educ. 71 (4): 67.

[20] Kaufman, L., and Rousseeuw, P. J. 2008. Finding Groups in Data: An Introduction to Cluster Analysis. Hoboken, NJ: John Wiley and Sons.

[21] Vermunt, J. K., and Magidson, J. 2002. "Latent Class Cluster Analysis." In Applied Latent Class Analysis. Cambridge: Cambridge University Press, 89-106.

[22] Severiens, S. E., and Ten Dam, G. T. M. 1994. "Gender Differences in Learning Styles: A Narrative Review and Quantitative Meta-analysis.” Higher Education 27 (4): 487-501.

[23] Ryan, R. M., and Deci, E. L. 2000. "Intrinsic and Extrinsic Motivations: Classic Definitions and New Directions." Contemp. Educ. Psychol. 25: 54-67.

[24] Driesen, A., Leemans, L., Baert, H., and Laekeman, G. 2005. "Flemish Community Pharmacists' Motivation and Views Related to Continuing Education." Pharmacy World and Science 27: 447-52.

[25] Power, A., Johnson, B. J., Diack, H. L., McKellar, S., Stewart, D., and Hudson, S. A. 2008 "Scottish Pharmacists' Views and Attitudes towards Continuing Professional Development." Pharmacy World and Science 30: 136-43.

[26] Wilbur, K. 2010 "Continuing Professional Pharmacy Development Needs Assessment of Qatar Pharmacists." International Journal of Pharmacy Practice 18: 236-41. 